Original Research Paper

\title{
Workshop Teknik-Teknik Evaluasi Proses Pelaksanaan Pemenuhan Mutu Sebagai Dasar Pelaksanaan Merdeka Belajar di SMA NW Narmada Lombok Barat
}

\author{
Sudirman Wilian ${ }^{1}$, Nyoman Sridana ${ }^{2}$ Dadi Setiadi $^{3 *}$

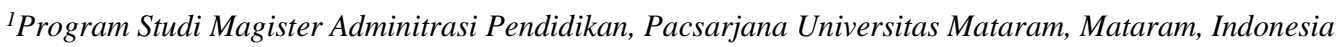

https://doi.org/10.29303/jpmpi.v3i2.610

Sitasi: Wilian, S., Sridana, N., \& Setiadi, D. (2021). Workshop Teknik-Teknik Evaluasi Proses Pelaksanaan Pemenuhan Mutu Sebagai Dasar Pelaksanaan Merdeka Belajar di SMA NW Narmada Lombok Barat. Jurnal Pengabdian Magister Pendidikan IPA, 4(1)

\section{Article history}

Received: 05 Desember 2020

Revised: 30 Desember 2020

Accepted: 02 Februari 2021

*Corresponding Author:

Dadi Setiadi, Program

Studi Magister Administrasi

Pendidikan, Pascasarjana,

Universitas Mataram,

Indonesia;

Email :

setiadi_dadi@unara.ac.id

\begin{abstract}
Mutu pendidikan SMA swasta di Kab Lombok Barat masih perlu ditingkatkan agar bisa memenuhi stándar nasional pendidikan. Kualitas pendidikan satuan pendidikan merupakan tingkat kesesuaian antara penyelenggaraan satuan pendidikan dengan Standar Nasional Pendidikan pada pendidikan menengah. Untuk bisa meningkatkan mutu tersebut diantaranya memiliki sistem penjaminan mutu internal yang merupakan suatu mekanisme yang sistematis, terintegrasi, dan berkelanjutan untuk memastikan bahwa seluruh proses penyelenggaraan pendidikan telah sesuai dengan standar mutu Tujuan dari kegiatan pengabdian kepada masyarakat adalah untuk memberikan pemahaman kepada para guru secara komprehensif terkait dengan bagaimana ; Melakukan monitoring dan evaluasi pelaksanaan pemenuhan mutu di SMA. yang digunakan dalam pengabdian kepada masyarakat ini adalah dalam bentuk pelatihan atau workshop yang lebih berbasis pada praktek langsung menyusun instrumen monitoring dan evaluasi pelaksanaan pemenuhan mutu, melaksanakan monitoring dan evaluasi pemenuhan mutu, menginterpretasi hasil dan menyusun tindak lanjut dari hasil tersebut berupa program mutu yang bisa menjamin peningkatan mutu di sekolah secara keseluruhan. Data hasil pengabdian dikumpulkan melalui asesmen pengetahuan dan keterampilan mengenai pemetaan mutu dan dianalisis secara deskriptif kualitatif. Guru peserta memiliki pemahaman komprehensif tentang standar nasional pendidikan, mutu untuk setiap standar nasional pendidikan ; dan terampil dalam mendesain instrumen-instrumen untuk monitoring pemenuhan mutu, dan untuk evaluasi pemenuhan, monev pelaksanaan pemenuhan mutu serta dalam menginterpretasi data hasil monev pelaksanaan pemenuhan mutu khususnya untuk tidak lanjut dari hasil pemenuhan mutu di sekolah.
\end{abstract}

Keywords: Standar Mutu Pendidikan; Program Mutu

\section{Pendahuluan}

Pemetaan mutu merupakan proses terkait kegiatan pengumpulan, pengolahan, analisis data dan informasi tentang capaian pemenuhan standar nasional pendidikan dari mulai tingkat sekolah, kabupaten/kota, provinsi, hingga nasional (Sekretariat Direktorat Jenderal Pendidikan Dasar dan Menengah, 2017). Pemetaan mutu tersebut memberikan gambaran kepada banyak pemangku kepentingan khususnya pengelola pendidikan di tingkat sekolah tentang capaian pemenuhan mutu. Salah satu tahapan yang harus dilakukan dalam menjalankan penjaminan mutu pendidikan di sekolah adalah penjaminan internal maupun eksternal. 
Sekolah melakukan kegiatan pemetaan mutu melalui evaluasi diri sekolah (EDS) dan menyampaikan hasil evaluasi tersebut dalam bentuk data dan informasi sesuai dengan instrumen pemetaan mutu yang dikembangkan oleh Direktorat Jenderal Pendidikan Dasar dan Menengah. Data dan informasi tersebut secara umum bisa memberikan gambaran terkait dengan mutu sekolah dan data tersebut dikirim ke sistem informasi mutu pendidikan untuk diolah menjadi peta mutu yang memuat capaian pemenuhan standar nasional pendidikan untuk disampaikan kepada sekolah. Peta mutu dianalisis lebih lanjut sehingga dapat digunakan sebagai acuan perencanaan pendidikan oleh sekolah khususnya dan pemerintah daerah/pusat, sehingga upaya pemenuhan mutu pendidikan di SMA bisa berjalan sinergis. Selain itu guru atau tim mutu sekolah harus melakukan monitoring dan evaluasi tentang proses pelaksanaan pemenuhan mutu.

Berdasarkan studi awal di lapangan khususnya pada guru dan tenaga kependidikan SMA Swastadi Narmada belum memiliki pemahaman dan keterampilan yang komprehensif dan sama dalam melaksanakan program penjaminan mutu di satuan pendidikan. Sebagai langkah awal penjaminan mutu yaitu para guru dan tenaga kependidikan harus memahami teknik monitoring dan evaluasi pelaksanaan pemenuhan mutu termasuk indikator-indikatornya. Selain itu warga sekolah belum memahami secara baik bagaimana melakukan monitoring dan evaluasi pelaksanaan pemenuhan mutu.

Dari uraian di atas, untuk menyelesaikan masalah tersebut yang dihadapi oleh para guru-guru SMA Swasta di Narmada Lombok Barat, maka diajukan salah satu solusi dengan cara memberikan workshop kepada guru-guru dan tenaga kependidikan yang lebih berbasis pada praktek dan pembimbingan langsung. Dengan tujuan para guru memahami dan terampil dalam penyusunan instrumen, dan teknik pelaksanaan pemetaan mutu serta tindak lanjut dari hasil pemetaan mutu tersebut.

\section{Metode}

Waktu pelaksanaan pengabdian kepada masyarakat dilaksanakan mulai bulan Mei sampai dengan bulan Juni 2020 bertempat di SMA Nahdatul Wathan Narmada Lombok Barat untuk kegiatan intinya dan kegiatan mandiri yang akan dikunjungi oleh tim pengabdian dan sekaligus melakukan monitoring dan evaluasi tentang pelaksanaan pengabdian. .Peserta pengabdian adalah semua guru SMA Nahdatul Wathan Narmada Lombok Barat kurang lebih berjumlah 30 orang termasuk tenaga kependidikan.

Pendekatan yang digunakan dalam kegiatan pengabdian ini dengan kegiatan berupa pelatihan/workshop yang lebih berbasis pada praktek langsung dan pembimbingan yang sifatnya lebih mentoring. Para guru diberikan pembekalan pemahaman lebih dulu tentang teknik menyusun instrumen untuk monev pemenuhan mutu di satuan pendidikan menengah. Instrumen tersebut akan menyangkut semua program terkait standar nasional pendidikan serta aplikasinya dalam monev pelaksanaan pemenuhan mutu di sekolah. Setelah itu guru kembali ke sekolah untuk berlatih menyusun instrumen monev pemenuhan mutu yang bisa mengukur kondisi pelaksanaan program mutu yang sesungguhnya agar tindak lanjut dalam program-program mutu selanjutnya bisa tepat dan maksimal, kemudian kembali dikumpulkan untuk mengkaji apa yang sudah dilakukan oleh para guru tersebut, setelah itu diberikan penjelasan atau saransaran perbaikan-perbaikan. Kemudian dilakukan pemantauan dan pembimbingan sampai dengan guru peserta pengabdian kepada masyarakat memiliki kemampuan yang baik dalam membuat instrumen monev pelaksanaan pemenuhan mutu yang bisa menggambarkan kondisi mutu yang sesungguhnya

\section{Hasil dan Pembahasan}

Hasil menunjukan bahwa para guru peserta pengabdian kepada masyrakat sebanyak 85 persen telah memiliki pemahaman komprehensif standar nasional pendidikan untuk pendidikan menengah, tetapi masih perlu penjabaran lebih lanjut terkait dengan standar tersebut, termasuk juga dalam penjabaran standar keompetensi lulusan, standar isi dan proses serta evaluasi. Hal tersebut penting untuk mencapai tujuan dari kurikulum. Banyak cara dalam mengembangan keterampilan guru dalam menjabarkan dan menerapkan tagihan dari standar standar tersebut lebih khsusus bagaimana bisa memenuhi tagihan merdeka 
belajar bagi siswa,

Selain hal tersebut di atas $87 \%$ guru juga telah miliki pemahaman tentang mutu untuk setiap standar nasional pendidikan. Hal ini penting untuk mengetahui standar mutu dari standar pendidikan. Berdasarkan pemahaman tersebut bisa mengembangkan atau meningkatkan mutu di atas standar nasional pendidikan, sehingga mutu proses dan hasil belajar akan tetap meningkat sesuai dengan program sekolah dalam meningkatkan mutu untuk mencapai atau melebihi standar nasional pendidikan. Jika guru sebagian besar bahkan semuanya memahami hal tersebut akan saling memberikan masukan jika semua program mutu tidak atau belum memenuhi standar nasional.

Untuk lebih baik lagi dalam membuktikan pemenuhan standar pendidikan guru perlu memiliki keterampilan dalam mendesain instrumen-instrumen untuk monitoring pemenuhan mutu satuan pendidikan menengah. Dari hasil asemen menunjukan bahwa sejumlah $85 \%$ guru terampil dalam menyusun instrumen monitoring pemenuhan mutu, dengan demikian guru akan saling memantau dan bekerja sama dengan tim sistem penjaminan mutu internal dalam mengases dan hasil program mutu yang ada di sekolah. Dengan demikian monitoring akan semakin baik terkait program mutu dan akan berdampak pada perbaikan program mutu sekolah.

Sejumlah $79 \%$ guru telah terampil dalam mendesain instrumen-instrumen untuk evaluasi pemenuhan mutu satuan pendidikan menengah. Hal tersebut akan berdampak pada bagaimana para guru di sekolah tersebut dapat menyusun program mutu yang sesuai dan dapat mengetahui sejauh man ingkat ketercapaian untuk pemenuhan mutu sesuai dengan program mutu yang sudah disusun. Namun demikian masih perlu tindak lanjut untuk pengembangan keterampilan tersebut mealalui bimbingan pengawas sekolah atau dijadikan bahan pembahasan di pertemuan rutin MGMP karena hal tersebut penting dalam menjamin mutu pendidikan di sekolahnya. Instrumen yang baik akan memberikan informasi terkait dengan gamabaran pencapaian mutu di sekolah, jika instrumennya tidak tepat maka akan berdampak pada rendahnya penilaian dari tim SPME.

Sejumlah $78 \%$ guru terampil dalam teknik monev pelaksanaan pemenuhan mutu pendidikan di satuan pendidikan menengah, hal ini menunjukan bahwa guru akan bisa melakukan monitoring pemenuhan mutu yang diprogramkan oleh sekolah termasuk tim penjaminan mutu internal, Selain itu bisa memberikan masukan terkait dengan pemenuhan mutu sesuai dengan merdeka belajar baik bagi peserta didik maupun bagi guru. Dengan demikian diharapkan kualitas pemenuhan mutu akan semakin baik dan kualitas peserta didik akan semakin meningkat.

Hal lain yang sangat penting adalah bagaimana guru bisa menginterpretasi atau menterjemahkan hasil evaluasi program mutu sekolah. Sejumlah $70 \%$ guru mampu menginterpretasi hasil evaluasi program mutu. Hal ini penting karena akan berdampak pada penyurusunan program program mutu berikutnya. Jika salah dalam menginterpretasi maka program mutu yang dikembangkan tidak akan sesuai dengan kondisi sekolah yang akan berdampak gagalnya program mutu sekolah. Dengan demikian perlu kehati-hatian bahkan akan lebih baik jika guru diberikan bimbingan untuk sekian kali dalam interpretasi hasil evaluasi program mutu sekolah.

Secara keseluruhan rata rata kompetensi guru mencapai $78 \%$ terkait dengan komptensi pemahaman standar nasional pendidikan, mutu untuk setiap standar nasional pendidikan; keterampil dalam mendesain instrumen-instrumen untuk monitoring pemenuhan mutu dan evaluasi pemenuhan mutu serta keterampilan dalam monev pelaksanaan pemenuhan mutu pendidikan di satuan pendidikan menengah. Juga dalam menginterpretasi data hasil monev pelaksanaan pemenuhan mutu untuk tidak 
lanjut sudah baik, namun masih perlu pendampingan dengan melibatkan unsur terkait, sehingga semua guru memahai dan terampila dalam pengembangan mutu di sekolahnya

\section{PEMBAHASAN}

Pemahaman guru tentang standar nasional pendidikan untuk pendidikan menengah sudah cukup baik. Standar isi merupakan ruang lingkup materi dan tingkat kompetensi yang dituangkan dalam kriteria tentang kompetensi tamatan, kompetensi bahan kajian, kompetensi mata pelajaran, dan silabus pembelajaran yang harus dipenuhi oleh peserta didik pada jenjang dan jenis pendidikan tertentu (https://bsnpindonesia.org/standar-nasional-pendidikan/).

Standar proses merupakan standar nasional pendidikan yang berkaitan dengan pelaksanaan pembelajaran pada satu satuan pendidikan untuk mencapai standar kompetensi lulusan (https://bsnpindonesia.org/standar-nasional-pendidikan/). Dari pengertian di atas, ada beberapa hal yang perlu digaris bawahi. Pertama, standar nasional pendidikan yang berarti bahawa standar ini berlaku untuk setiap lembaga pendidikan formal pada jenjang pendidikan tertentu dimanapun pendidikan itu berada secara nasional. Setiap satuan pendidikan harus melakukan perencanaan proses pembelajaran, pelaksanaan proses pembelajaran, penilaian hasil pembelajaran, dan pengawasan proses pembelajaran untuk terlaksananya proses pembelajaran yang efektif dan efisien (Jaya, dan Ellyawati. 2019). Selain itu metode pembelajaran harus sesuai dengan tagihan hasil secara keseluruhan untuk setiap kurikulum yang berlaku terdapat sejumlah metode yang direkomendasikan agar bisa mencapai indikator pencapaian kompetensi. (Jekti, dkk, 2018)

Standar Kompetensi Lulusan (SKL) merupakan sumber atau rujukan utama dalam menentukan standar proses pendidikan (https://bsnp-indonesia.org/standar-nasional pendidikan/). Ditujukan untuk pendidikan dasar dan pendidikan menengah dalam menentukan kelulusan peserta didik dan pedoman penilaian. Standar kompetensi lulusan digunakan sebagai pedoman penilaian dalam penentuan kelulusan peserta didik dari satuan pendidikan.
Standar Pendidik dan Tenaga Kependidikan. Hal ini bahwa "guru dan kepala sekolah merupakan pelaku profesi yang harus menerapkan kompetensinya sebagai tenaga pendidik secara maksimal dengan memenuhi beberapa ketentuan, sehingga dapat menciptakan out put yang diharapkan oleh intansi pendidikan (https://bsnp-indonesia.org/standar-nasional-

pendidikan/). Untuk memaksimalkan potensi sekolah termanfaatkan dalam pengelolaannya, sekolah hendaknya memiliki tenaga administrasi yang mampu dan memahami tentang tata administrasi sekolah, sehingga tenaga pendidik dan kependidikan di sekolah tidak kehilangan data tentang inventarisasi sekolah.'Pendapat tentang pencapaian standar pendidik dan tenaga kependidikan tersebut, memberikan gambaran bahwa secara umum diharapkan sekolah memiliki tenaga pendidik dan kependidikan yang memiliki standar sesuai dengan BSNP dan mampu menerapkan kompetensinya secara maksimal. Selain itu teachers should not only have the competencies that have been established, but also must have the ability multi-literacy, insightful nationality, and global perspective (Lisnawati, 2018).

Standar Proses pembelajaran seharusnya interaktif, inspiratif, menyenangkan, menantang, memotivasi peserta didik untuk berpartisipasi aktif serta memberikan ruang yang cukup bagi prakarsa, kreativitas dan kemandirian sesuai dengan bakat, minat dan perkembangan fisik serta psikologis peserta didik (https://bsnp-indonesia.org/standarnasional-pendidikan/).

Standar Sarana dan Prasarana, Pengelolaan yang dilakukan sekolah terhadap standar sarana dan prasarana yang dimiliki telah dapat disesuaikan dengan standar nasional pendidikan dan tidak memiliki perbedaan yang mendasar pada sekolah swasta dan sekolah negeri (https://bsnpindonesia.org/standar-nasional-pendidikan/).

Standar pengelolaan pada sekolah swasta dan sekolah negeri dalam wilayah kerja UPT Disdik telah memiliki standar nasional pendidikan dan dapat memberikan pengalaman khusus bagi peneliti dalam mengamati dan meneliti semua yang telah dilakukan oleh manajemen sekolah (https://bsnp-indonesia.org/standar-nasionalpendidikan/).

Standar pembiayaan dalam pengelolaan sekolah swasta dan sekolah negeri secara umum 
telah memiliki orientasi untuk memberikan sebaran pembiayaan sesuai dengan prioritas masing-masing dalam beberapa item pembiayaan. Pelaksanaan RKAS oleh kepala sekolah dan bendahara dilakukan secara terbuka dan bertanggung jawab dan tidak dilakukan hal-hal yang menyimpang dalam pembayaran gaji, honor kegiatan serta pembelajaan barang.

Standar Penilaian, Pelaksanaan standar pengelolaan penilaian yang dilakukan oleh sekolah swasta dan sekolah negeri telah dilakukan secara kondusif dan memiliki langkah-langkah yang terencana dimulai dari persiapan, pelaksanaan dan tindak lanjut (https://bsnp-indonesia.org/standarnasional-pendidikan/). Persiapan yang dilakukan dengan membentuk tim, menyusun kisi-kisi, dan menyusun soal secara rapi dan jelas. Pencapaian standar penilaian yang diterapkan di sekolah swasta dan sekolah negeri tidak terdapat perbedaan dan tetap berdasarkan pada BSNP, akan tetapi tindak lanjut hasil penilaian yang dilakukan pada sekolah swasta lebih mendorong pada siswa untuk mampu menuntaskan KKM yang telah ditetapkan.

Pemahaman tentang mutu untuk setiap standar nasional pendidikan sudah sangat baik artinya para guru sudah memahami indikator indikator mutu untuk setiap standar nasional pendidikan, sehingga akan lebih mudah dalam membuat program untuk bisa memenuhi indikator mutu dari standar nasional pendidikan. Hal tersebut terlebih dahulu bisa dilakukan melalui pemetaan mutu sekolahnya sebagi gambaran tenatnag seberapa besar pencapaian standar nasional pendidikan. Proses pemetaan mutu terkait kegiatan pengumpulan, pengolahan, analisis data dan informasi tentang capaian pemenuhan standar nasional pendidikan pada tingkat sekolah, Informasi tersebut bisa memberikan gambaran kepada berbagai pemangku kepentingan tentang capaian pemenuhan standar nasional pendidikan dari satuan pendidikan tersebut (Kementerian Pendidikan dan Kebudayaan, 2020)

Keterampilan guru alam mendesain instrumen-instrumen untuk monitoring pemenuhan mutu satuan pendidikan menengah masih perlu ditingkatkan. Hal tersebut disebabkan untuk dapat menyusun instrument monev perlu memahami secara menyeluruh tentang terkait dengan perencanaan dan pelaksanaan tentang pemenuhan mutu satuan pendidikan. Dengan demikian guru harus diberikan lebih mendalam lagi terkait dengan bagimana yang dilakukan sekolah untuk bisa memenuhi mutu sesuai dengan tagihan dari standar nasional pendidikan yang menyngkut 8 standar nasiona peldidikan. Keterampilan tersebut sangat bermanfaat bagi sekolah untuk bisa memperbaiki dan meningkatkan program program pemenuhan mutu, sehingga dari tahun ke tahun mutu sekolah akan semakin baik.

Keterampilan guru dalam mendesain instrumen-instrumen untuk evaluasi pemenuhan mutu satuan pendidikan menengah dan melaksanakan pengukuran mutu pendidikan di satuan pendidikan masih perlu ditingkatkan nhal tersebut bisa disebabkan pemahaman guru tentang indikator pemenuhan mutu belum dipaham secara komprehensif sehaingga instreumen yang disusun belum sepenuhnya memenuhi ntagihan untuk bisa mengukur pemenhuan mutu tersebut. Hal ini perlu mendapat perhatian jika instrument yang disusun tidak atau belum tepata sehingaga tidak bisa memberikan gambaran yang sesungguhnya tentan pencapian pemenuhan mutu untum stndar nasional pemdidikan. Instrumen yang disusun harus sesuai dengan indikator pemenuhan mutu sehingga perlu narasumber yang betul memenuhi kualifikasi dalam hal pemenuhan stndar nasional pendidikan dan pengukurannya.

Keterampilan guru dalam monev pelaksanaan pemenuhan mutu pendidikan di satuan pendidikan menengah guru namun untuk lebih baiknya perlu ditingkatkan, hal tersebut bisa disebabkan guru belum memenuhi dengan baik bagaimana pelaksanaan program pemenuhan mutu dan siapa siapa saja yang melaksankaanya serta tagihan apa saja yang harus dilakaukan ketikan melaksanakan pemenuhan mutu pendidikan di satuan pendidikan. Satu hal yang sanagt penting dalam monitoring evaluasi pemenuhan mutu pendidikan adalah pemahaman yang menyeluruha dan objektifitas yang harus tetap dijaga agar bisa memberikan gamabara sebenarnya tentang proses peleksanaan pemenuhan mutu. Jika demikian makaakan di ketahui kelemahan dan bisa disusun tindak lanjut untuk memperbaiki proses tersebut. Penetapan standar baru dan penyusunan strategi peningkatan mutu berdasarkan hasil monitoring dan evaluasi (Sridana, Wilian, dan Setiadi, 2018)

Keterampilan dalam menginterpretasi data hasil monev pelaksanaan pemenuhan mutu untuk tidak lanjut dari hasil pelaksanaan pemenuhan mutu di sekolah masih belum baik ntuk semua guru, 
sehingga masih perlu ditingkatkan. Kekurangn tersebut diantanranya bisa disebabkan kekurang pamahaman guru secara menyeluruh tentang program pemenuhan mutu pendidikan. Guru harus terampil secara baik dalam menginterpretasikan hasil pemetaan mutu pendidikan di satuan pendidikan menengah, dimana keterampilan tersebut sangat penting karena akan terkait dengan kegiatan berikutnya yaitu penyusunan prograprogram mutu. (Wilian, dkk, 2019).

Selain itu bapak ibu guru harus terlebih diperkuat dalam pemahaman terkait dengan pemenuhan mutu satuan pendidikan dan kemudian diberikan penguatan dalam teknik analisis data pelaksanaan program pemenuhan mutu. pembimbingan lebih detail lagi dan praktek lebih banyak lagi merupakan cara untuk lebih memberikan pengalaman agar guru bisa memiliki keterampilan sangat baik (Jufri, dkk, 2019). Keterampilan interpretasi sangat penting karena menentukan langkah perbaikan berikutnya, jika tidak tepat dalam menginterpretasi maka akan menyebabkan program program pemenuhan mutu berikutnya tidak sesuai dengan yang dibutuhkan yang akan berakibat pemenuhan mutu tidak bisa dicapai secara maksimal. Selain itu pelaksanaan pengumpulan data, pemrosesan data, analisa data, pelaporan, dan rekomendasi yang ditindak lanjuti dengan implementasi (Ramdani, Witono, dan Sukardi, 2018)

Kegiatan workshop teknik-teknik monitoring dan evaluasi proses pelaksanaan pemenuhan mutu di SMA NW Narmada secara keseluruhan memberikan manfaat dalam peningkatan pemahaman terkait bagaimana pemenuhan mutu pendidikan termasuk pelaksanaan monevnya sehingga bisa memberikan manfaat bagi lembaga dalam memperbaiki proses pemenuhan mutu. Selain itu berdampak pada sekolah lain satu gugus dalam hal bagaimana caranya melakukan monev pelaksanaan program program pemenuhan mutu di sekolah masing masing.

\section{Kesimpulan}

Guru memiliki pemahaman komprehensif standar nasional pendidikan, mutu untuk setiap standar nasional pendidikan; dan terampil dalam mendesain instrumen-instrumen untuk monitoring pemenuhan mutu dan mendesain instrumen-instrumen untuk evaluasi pemenuhan dan dalam monev pelaksanaan pemenuhan mutu pendidikan dalam menginterpretasi data hasil monev pelaksanaan pemenuhan mutu untuk tidak lanjut dari hasil pelaksanaan pemenuhan mutu di sekolah.

\section{Ucapan Terima Kasih}

Ucapan terima kasih disampaikan kepada bapak Rektor Universitas Mataram atas dukungan biaya Pengabdian dan Kepada kepale sekolah dan bapak /Ibu guru atas dukungan dan partisipasinya.

\section{Daftar Pustaka}

Damanik, J. 2015. Upaya dan Strategi Pemenuhan Standar Nasional Pendidikan. J D P, Vol. 8 (3) $151-160$.

Direktorat Jenderal Pendidikan Dasar dan Menengah. 2016. Pedoman Umum Sistem Penjaminan Mutu Pendidikan Dasar dan Menengah. Jakarta : Direktorat Jenderal Pendidikan Dasar dan Menengah Kementrian Pendidikan dan Kebudayaan.

Direktorat Jenderal Pendidikan Dasar dan Menengah. 2016. Petunjuk Pelaksanaan Penjaminan Mutu Oleh Satuan Pendidikan. Jakarta: Direktorat Jenderal Pendidikan Dasar dan Menengah Kementerian Pendidikan dan Kebudayaan

Hidayah,I., Susilowati, E., dan Sukirman. 2014. Analisis Pembiayaan Pendidikan SMA dI Kota Semarang. Riptek Vol. 8 (2) 13 - 22.

Jekti, D. S. D., Bachtiar, I., Sedijani, P. Zulkifli, L. dan Setiadi, D., 2018. Perangkat Pembelajaran IPA Model 5E : Kajian Kritis Hasil Workshop Guru Guru Anggota MGMP IPA Kota Mataram. Jurnal Pengabdian Magister Pendidikan IPA. (1) $1: 12-19$

Jufri, A. W., Suryanti, N.M.N., Amin, M., Jaelani, A. K. dan Setiadi, D. 2019. Workshop Teknik Pembimbingan dan Penilaian Mahasiswa Peserta Praktek Pengenalan Lapangan Persekolahan Bagi Guru-Guru Anggota KKG di Kota Mataram . Jurnal Pengabdian Magister Pendidikan IPA. (2) 2: 133-138.

Mahsun, H. 2013. Strategi Peningkatan Mutu Pendidikan Melalui Manajemen Berbasis Sekolah. Media Bina Ilmiah. Vol. 7 (6). 
Menteri Pendidikan dan Kebudayaan Republik Indonesia, 2016. Peraturan Menteri Pendidikan dan Kebudayaan Republik Indonesia Nomor 28 Tahun 2016 Tentang Sistem Penjaminan Mutu Pendidikan Dasar dan Menengah. Jakarta: Kementerian Pendidikan dan Kebudayaan.

Pemerintah Republik Indonesia. 2003. Undangundang Nomor 20 Tahun 2003 tentang Sistem Pendidikan Nasional. Jakarta: Pemerintah Republik Indonesia.

Puspitasari, H. 2017. Standar Proses Pembelajaran Sebagai Sistem Penjaminan Mutu Internal di Sekolah. Muslim Heritage. Vol. 1 (2).

Raharjo, S. B. 2014. Kontribusi Delapan Standar Nasional Pendidikan Terhadap Pencapaian Prestasi Belajar. Jurnal Pendidikan dan Kebudayaan, Vol. 20 (4)

Ramdani, A., Witono, A. H. dan Sukardi, 2018. Pelatihan Pengisian Instrumen Akreditasi Untuk Peningkatan Mutu Evaluasi Diri Sekolah/Madrasah Pada Kelompok Kerja Madrasah Aliyah Wilayah IV. Jurnal Pengabdian Magister Pendidikan IPA. (1) $1: 32-36$.

Sekretariat Direktorat Jenderal Pendidikan Dasar dan Menengah, 2017. Perangkat Instrumen Pemetaan Mutu Pendidikan Dasar dan Menengah Tingkat Sekolah Menengah Atas. Jakarta : Sekretariat Direktorat Jenderal Pendidikan Dasar dan Menengah Kementerian Pendidikan dan Kebudayaan.

Sridana, N., Wilian, W. dan Setiadi, D. 2018. Sistem Penjaminan Mutu Internal Di Satuan Pendidikan Menengah (SMA). Jurnal Pengabdian Magister Pendidikan IPA, (1) $1: 45-51$.

Wilian, S., Wildan, Sridana, N., dan Setiadi, D., 2019. Workshop Teknik-Teknik Pemetaan Mutu Pendidikan di Satuan Pendidikan Bagi Guru-Guru di SMA Muhammadiyah Mataram. Jurnal Pengabdian Magister Pendidikan IPA, (2) 2 : 122-126. 